\title{
Die Antwort der deutschen Bischöfe an die polnischen Bischöfe vom 5. Dezember 1965
}

Hochwürdigste Mitbrüder im bischöflichen Amt!

Mit Bewegung und Freude haben wir Ihre Botschaft vom 18. November dieses Jahres und Ihre freundliche Einladung zur Tausendjahrfeier der Christianisierung des polnischen Volkes empfangen. Wir betrachten es als eine kostbare Frucht unserer gemeinsamen Konzilsarbeit, daß Sie dieses Wort an uns richten konnten. Dankbar greifen wir es auf und hoffen, den begonnenen Dialog in Polen und in Deutschland miteinander fortsetzen zu können. Mit Gottes Hilfe wird dieses Gespräch die Brüderlichkeit zwischen dem polnischen und dem deutschen Volk fördern und festigen.

Wir sind uns bewußt, wie schwer es für viele Christen in Europa war und noch ist, nach den Schrecken des Zweiten Weltkrieges die fundamentale Wahrheit unseres Glaubens mit ganzem Herzen festzuhalten, daß wir Kinder des himmlischen Vaters und Brüder in Christus sind. Diese christliche Brüderlichkeit fand im Jahre 1948 beim Kölner Domjubilämn durch den Besuch französischer und englischer Kardinäle und Bischöfe ihren ersehnten Ausdruck. So möge auch im kommenden Jahr das Millenium der Taufe Polens ein solches Zeichen werden.

Sie haben uns in Ihrem Schreiben, ehrwürdige Brüder, in Erinnerung gerufen, mit wie vielen Banden das polnische Volk seit Jahrhunderten an das christliche Europa gebunden ist und welche Rolle es in der Geschichte dieses christlichen Europas gespielt hat und, so hoffen wir, auch weiterhin spielen wird. Sie hatten dabei die Großherzigkeit, aus all diesen Jahrhunderten zunächst und vor allem Beispiele zu erwähnen, die sowohl Ihrem wie auch unserem Volke zur Ehre gereichen, Beispiele gemeinsamer Arbeit, aufrichtiger Achtung, fruchtbaren Austausches und gegenseitiger Förderung, obwohl dies alles hätte zurücktreten können 
angesichts des Unrechts und des Leides, das das polnische Volk im Laufe der Geschichte zu tragen hatte. Es ist ein tröstlicher Hinweis auf die von uns erhoffte und mit allen Mitteln zu erstrebende Zukunft, wenn Sie uns daran erinnern, wie die polnische Kirche im Mittelalter über alle Grenzen hinweg mit deutschen Städten, Gemeinden und Orden in vielfältigem Austausch gestanden hat. Es berührt uns tief, daß wir in der Verehrung der heiligen Hedwig vereint sind, die deutschen Geblütes und doch wie Sie schreiben die größte Wohltäterin des polnischen Volkes im 13. Jahrhundert war. Diese hellen Seiten des polnischdeutschen Verhältnisses in der Geschichte verdanken wir ohne Zweifel unserem gemeinsamen christlichen Glauben. Wir sind daher überzeugt und mit Ihnen, ehrwürdige Brüder, darin einig: Wenn wir über alle Unterschiede hinweg Brüder Christi sein wollen, wenn wir Bischöfe, wie es bei diesem Konzil deutlich wurde, zuerst und vor allem das Kollegium der Hirten sein wollen, die dem einen Volke Gottes dienen, und wenn wir so auch unsere Teilkirchen führen, dann müssen die Schatten weichen, die leider noch immer über unseren beiden Völkern liegen.

Furchtbares ist von Deutschen und im Namen des deutschen Volkes dem polnischen Volke angetan worden. Wir wissen, daß wir Folgen des Krieges tragen müssen, die auch für unser Land schwer sind. Wir verstehen, daß die Zeit der deutschen Besatzung eine brennende Wunde hinterlassen hat, die auch bei gutem Willen nur schwer heilt. Um so mehr sind wir dankbar, daß Sie angesichts dieser Tatsache mit wahrhaft christlicher Großmut anerkennen, wie in der Zeit des Nationalsozialismus auch ein großer Teil der deutschen Bevölkerung unter schwerem Gewissensdruck gestanden hat. Wir sind dankbar, daß Sie auch angesichts der Millionen polnischer Opfer jener Zeit sich an die Deutschen erinnern, die dem Ungeist widerstanden und zum Teil ihr Leben hingegeben haben. Es ist uns ein Trost, daß viele unserer Priester und Gläubigen in jener Nacht des Hasses betend und opfernd für das entrechtete polnische Volk eingetreten sind und für diese christliche Liebe Gefängnis und Tod auf sich genommen haben. Wir sind dankbar, daß Sie neben dem unermeßlichen Leid des polnischen Volkes auch des harten Loses der Millionen vertriebener Deutscher und Flüchtlinge gedenken.

Eine Aufrechnung von Schuld und Unrecht - darin sind wir einer Meinung - kann uns freilich nicht weiterhelfen. Wir sind Kinder des gemeinsamen himmlischen Vaters. Alles menschliche Unrecht ist zunächst eine Schuld vor Gott, eine Verzeihung muß zunächst von ihm erbeten werden. An ihn richtet sich zuerst die Vaterunserbitte „Vergib uns unsere Schuld!“ Dann dürfen 
wir auch ehrlichen Herzens um Verzeihung bei unseren Nachbarn bitten. So bitten auch wir zu vergessen, ja wir bitten zu verzeihen. Vergessen ist eine menschliche Sache. Die Bitte um Verzeihung ist ein Anruf an jeden, dem Unrecht geschah, dieses Unrecht mit den barmherzigen Augen Gottes zu sehen und einen neuen Anfang zuzulassen.

Dieser Anfang ist besonders belastet durch die bitteren Folgen des von Deutschland begonnenen und verlorenen Krieges. Millionen von Polen mußten aus dem Osten in die ihnen zugewiesenen Gebiete übersiedeln. Wir wissen wohl, was darum für das heutige Polen diese Gebiete bedeuten. Aber auch Millionen Deutsche mußten ihre Heimat verlassen, in der ihre Väter und Vorfahren lebten. Diese waren nicht als Eroberer in das Land gezogen, sondern im Laufe der Jahrhunderte durch die einheimischen Fürsten gerufen worden. Deshalb müssen wir Ihnen in Liebe und Wahrhaftigkeit sagen: Wenn diese Deutschen von „Recht auf Heimat" sprechen, so liegt darin von einigen Ausnahmen abgesehen keine aggressive Absicht. Unsere Schlesier, Pommern und Ostpreußen wollen damit sagen, daß sie rechtens in ihrer alten Heimat gewohnt haben und daß sie dieser Heimat verbunden bleiben. Dabei ist ihnen bewußt, daß dort jetzt eine junge Generation heranwächst, die das Land, das ihren Vätern zugewiesen wurde, ebenfalls als ihre Heimat betrachtet. Christliche Liebe versucht, sich jeweils in die Sorgen und Nöte des anderen hineinzuversetzen und so Spannungen und Grenzen zu überwinden. Sie will den Ungeist des Hasses, der Feindschaft und des Revanchismus ausmerzen. So wird sie dazu beitragen, daß alle unseligen Folgen des Krieges in einer nach allen Seiten befriedigenden und gerechten Lösung überwunden werden. Sie dürfen überzeugt sein, daß kein deutscher Bischof etwas anderes will und jemals etwas anderes fördern wird als das brüderliche Verhältnis beider Völker in voller Aufrichtigkeit und ehrlichem Dialog.

$\mathrm{Zu}$ solcher Brüderschaft des guten Willens kann uns die Erfahrung des Konzils Mut machen. Auch beim Konzil waren die Wege nicht immer überschaubar. Nicht immer leuchtete das Ziel klar und deutlich, und oft standen die Väter zögernd an Wegkreuzungen, aber dann wurde uns durch Gottes Gnade ein Weg gezeigt und manchmal eine überraschende Lösung geschenkt. So hoffen wir mit Ihnen, daß Gott auch unseren beiden Völkern in Zukunft Lösungen zeigen wird, wenn wir ihm Beweise unseres guten Willens geben. Als Zeichen unseres guten Willens, ehrwürdige Brüder, wollen wir, in aufrichtiger Dankbarkeit für Ihre Einladung, als Pilger zu Ihrem Marienheiligtum nach Tschenstochau kommen und Anteil nehmen an Ihrer 
248 Volume 3 (2013) Number 2, p. 245-249

und Ihres ganzen Volkes Freude. Wir wollen mit Ihnen an den Heiligtümern beten, wo das polnische Volk sich oft und besonders in der heutigen Zeit Kraft und Segen von Gott erbittet. Wir versprechen, unsere Gläubigen aufzufordern, sich im kommenden Marienmonat mit unserem und Ihrem Gebet zu vereinen.

Wir wollen alles tun, daß diese Verbindung nicht mehr abreißt. Im Jahr 1968 wird der Deutsche Katholikentag in Essen stattfinden. Im gleichen Jahr begeht das Bistum Meißen die Tausendjahrfeier seiner Gründung. Es wäre für uns und unsere Gläubigen eine große Freude, bei diesen Gelegenheiten polnische Bischöfe begrüßen zu dürfen. Bei unseren Einladungen haben wir mit Ihnen den Wunsch, daß die Begegnung der Bischöfe und der begonnene Dialog sich fortsetzen möge in allen Lebensbereichen unserer beiden Völker. Alle Schritte, die diesem Ziel dienen können, werden wir von Herzen begrüßen. Darum erfüllen wir auch mit Freude Ihre Bitte, Ihren besonderen Gruß unseren evangelischen Brüdern in Deutschland zu übermitteln. Darüber hinaus dürfen wir uns in unseren Bemühungen um gegenseitiges Verständnis einig wissen mit allen Menschen guten Willens.

Hochwürdigste Brüder! Das Konzil hat uns zusammengeführt an heiliger Stätte zu gemeinsamer Arbeit und gemeinsamem Gebet. Die Grotten von St. Peter bergen die kleine Kapelle der Tschenstochauer Madonna. Dort fanden wir auch das Bild der heiligen Hedwig, die Ihr Volk besonders verehrt und die Sie ,als den besten Ausdruck eines christlichen Brückenbaues zwischen Polen und Deutschland" ansehen.

Von dieser großen Heiligen wollen wir lernen, uns in Ehrfurcht und Liebe zu begegnen. Am Schluß Ihres Schreibens stehen die kostbaren Worte, die für unsere beiden Völker eine neue Zukunft eröffnen können: „Wir strecken unsere Hände zu Ihnen hin in den Bänken des zu Ende gehenden Konzils, gewähren Vergebung und bitten um Vergebung.“ Mit brüderlicher Ehrfurcht ergreifen wir die dargebotenen Hände. Der Gott des Friedens gewähre uns auf die Fürbitte der „regina pacis“, daß niemals wieder der Ungeist des Hasses unsere Hände trenne!

Rom, 5. Dezember 1965

Die Namen der deutschen Unterzeichner:

Jos. Card. Frings, Erzbischof von Köln, Julius Card. Döpfner, Erzbischof von München und Freising, Lorenz Card. Jaeger, Erzbischof von Paderborn, Josef Schneider, Erzbischof von Bamberg, Hermann Schäufele, Erzbischof von Freiburg, Alfred Bengsch, Erzbischof von Berlin, Joseph Schröffer, 
Bischof von Eichstätt, Franz Hengsbach, Bischof von Essen, Adolf Bolte, Bischof von Fulda, Hermann Volk, Bischof von Mainz, Rudolf Graber, Bischof von Regensburg, Isidor Marcus Emanuel, Bischof von Speyer, Carl Jos. Leiprecht, Bischof von Rottenburg, Josef Stangl, Bischof von Würzburg, Wilhelm Kempf, Bischof von Limburg, Matthias Wehr, Bischof von Trier, Josef Stimpfle, Bischof von Augsburg, Heinrich Maria Janssen, Bischof von Hildesheim, Helmut Hermann Wittler, Bischof von Osnabrück, Johannes Pohlschneider, Bischof von Aachen, Otto Spülbeck, Bischof von Meißen, Joseph Höffner, Bischof von Münster, Gerhard Schaffran, Bischof und Kapitelsvikar in Görlitz, Heinrich Pachowiak, Weihbischof in Hildesheim, Walter Kampe, Weihbischof in Limburg, Johannes v. RudIoff, Weihbischof in Hamburg, Augustinus Frotz, Weihbischof in Köln, Eduard Schick, Weihbischof in Fulda, Hugo Aufderbeck, Weihbischof in Erfurt, Joseph Buchkremer, Weihbischof in Aachen, Heinrich Tenhumberg, Weihbischof in Münster i.W., Alfons Kempf, Weihbischof in Würzburg, Julius Angerhausen, Weihbischof in Essen, Karl Gnädinger, Weihbischof in Freiburg, Joseph Zimmermann, Weihbischof in Augsburg, Carl Schmidt, Weihbischof in Trier, Friedrich Rintelen, Weihbischof in Magdeburg, Josephus Hiltl, Weihbischof in Regensburg, Wilhelm Cleven, Weihbischof in Köln, Bernardus Stein, Weihbischof in Trier, Bernhard Schräder, Weihbischof in Schwerin, Josef Maria Reuss, Weihbischof in Mainz 